\title{
Evidence Based Medicine in Cultural and Historical Context
}

\author{
(Julian) Zhunping Xue*
}

It is difficult to argue with the fundamental tenet of Evidence Based Medicine (EBM), the conscientious, explicit, and judicious use of current best evidence in making decisions about the care of individual patients ${ }^{i}$. What sane, ethical person or culture can deny something so obvious? As members of a dominating society, however, we forget how current practices derived from the past and we mistake the present to be the only possibility ${ }^{i i}$. Looked across time, EBM is the perfectly unique product of the West, embedded as we are in rationalityiii, and our particular brand of EBM, steeped in rational methodology: RCT, meta-analyses, guidelines and quantification ${ }^{\text {iv, }}$ is far less universal than we might believe.

Cries for EBM can be found as early as the late 18th century, but its modern carnation began in the 70's with figures such as Dr. Arthur Cochrane and John Wennberg ${ }^{\mathrm{V}}$. They denounced medicine as practiced then, based upon expert consensus and mental models which did not bear upon reality ${ }^{\mathrm{vi}}$. Existing evidence must be organized and used, they reasoned, and the need for new and better evidence also became apparent.

$\mathrm{i}$ - This definition is quite prevalent, see the beginning of Eddy 2005 (1) for example.

ii - Daniel Dennett (a famous living philosopher who thinks deeply about religion, evolution, and consciousness) likes to say do not mistake a failure of imagination for impossibility. See (2) for an example.

iii - This hardly warrants a reference, but John Ralston Saul has attacked rationalism so spectacularly that I feel compelled to direct readers to his book Voltaire's Bastards (3), chapter 4, where Saul traces the beginning of rationality to the Inquisition

iv - To be convinced, one merely needs to leaf through (4), which is almost completely methodological and devoted to RCT's and the like. However broad EBM is defined in philosophy, these methods are how it plays out in practice in our particular society.

$\mathrm{v}$ - This brief history of EBM is compiled from (1) and (5)

*To whom correspondence should be addressed: Julian Z. Xue

McGill University, Department of Biology,

Montreal, Canada, H3A 1B1

Email: zhunping.xue@mail.mcgill.ca
This is progress in all senses: they managed to reduce an immense cognitive dissonance within our society, a dissonance that leads laypeople to scratch their heads and ask: "... and what were they doing before that?"

Since then, EBM has spread with immense speed, but also have had its fair share of critics ${ }^{\text {vii }}$. Many explanations are given for this conflict, from a "sociology of professions"viii to lingering suspicions of laziness and closed-mindedness (by both sides), but one itch was never scratched: perhaps EBM is not culturally neutral. Perhaps it is a product of our Age of Reason ${ }^{\text {ix }}$, one of its crowning jewels, and its strengths and weaknesses are reflective of our society as a whole.

Our culture uniquely worships efficiency and certainty under the umbrella of rationality. In the classic narrative, we have come to this through a triumph of science as well as struggles for a more reasonable society against a whimful aristocracy ${ }^{\mathrm{x}}$. That almost all the evidence in EBM is used to further these goals cannot be called a coincidence; this is the deliberate (if often blind) action of a willful society. Evidence does not form its own goals! Indeed, evidence funded ill aims

vi - Goodman (5) is especially vehement about previous medical practice. On page 6: This percentage [of evidence-based practices] is always very low - it ranges from $10 \%$ to $25 \%$ of medical decisions. The numbers leave us slack-jawed. If clinicians decisions are based on (high-quality) evidence only $10 \%$ or $25 \%$ or even $50 \%$ of the time, then what on earth is guiding the rest of the decisions in which pain, suffering, disability and life hang in the balance?

Even Eddy (1) caricaturizes earlier practice with the physician as a trusted all-powerful being who in fact had little idea what they were doing. Although I cannot evaluate those years directly, such mocking makes me suspicious of historical rewriting of science by the victors, a la Kuhn (6). I have yet to meet an entire society of idiots.

vii - See (7). It raises suspicion that something so "basic and obvious" $(5$, p.7) should meet so much trouble. It's much too easy to slap the trouble with "ignorance".

viii - This is the explanation given by (7). I find it somewhat naive. ix - I found this phrase from Saul (3). My own world view is strongly influenced by Saul and Kuhn, as might become obvious throughout this essay. Although I do not agree with Saul in his extremism, I feel he really reaches the root when discussing the "dictatorship of reason" as the heart of many ills of modern society. $\mathrm{x}$ - Saul (3), chapters 1-5. 
in the past: Hitler's eugenics program was proudly based on statistics and eugenics itself was initiated by Sir Francis Galton, who cannot be accused of Hitler's political agendaxi. Yet who speaks of eugenics today?

Although all proponents of EBM speak of patient wellness, that wellness is phrased in terms of efficiency (low cost - high delivery), reducing uncertainty in physician decision making, and a rationalization (that is, a logicization) of the medical process from research to bedsidexii. These goals themselves, however, are dictated by our beliefs and culture - by rationalism. Even if there is data that patient outcomes are improved by EBM ${ }^{x i i i}$, one cannot ignore the constant grumbling by the general public of the inhumanity of scientific medicine - in the words of Paul Nadler, director of the film Braindamadj' $d$ : "when doctors see me, they see the $5 \%$, that I have 5\% chance of recovering, they see what they expect. They don't see the human, the me, the whole person."xiv This means that other goals are possible and laudable. They in fact belong to another cultural strand that existed within Western history alongside rationalism for many years: humanism.

When doctors advocate for whole-person care, when doctors lament the time pressures they work under, when patients complain bitterly about medical arrogance, they do not battle EBM, rather they battle the cultural network, rationalism, within which EBM is embedded. That is why combatants of both sides seem to talk over each others' heads: as protestors push against EBM, EBM supporters are bewildered: there is nothing in their cultural framework that could possibly negate EBM; protestors who are meshed in humanism, however, strive for very different goals, and they are bewildered because a tool is suddenly deciding goals - grossly inappropriate actions for a tool.

Carefully dissected, the deepest criticism of EBM all lie here: not EBM as a tool, but of the rationalistic weaknesses underlying EBM. Examples include how many questions are unanswerable in EBM, how important patient experiences are not included in EBM, how EBM is often misinterpreted and misused ${ }^{\mathrm{Xv}}$. The flailing against EBM is therefore a flailing against the culture of rationalization, a strong, ubiquitous current in our society. In this view, EBM is a powerful tool that predisposes us further towards that potentially dangerous current.

Is this rationalizing current dangerous? Yes it is ${ }^{\mathrm{xvi}}$. We sense far more than we can measure. Indeed, we sense far more than we can paint, sing, write. We all sense more than any culture can synthesize; each culture emphasizes a coherent portion of our sensed world. In the West, we have chosen measurement. For all its triumph, this done in excess will dull our other senses and we are reduced to sensing only that which we can measure. Extreme rationality impoverishes our abilities to empathize, to doubt and be heterogeneously human, and that trend we do not only see in medicine, but witness in the West as a whole. The reduction in doubt is particularly dangerous, as no self-correction can occur - a typical EBM answer to any problem is: more, better EBM. Yet that extra evidence requires resources to gather ${ }^{\mathrm{xvii}}$, an opportunity cost that is difficult to measure and therefore never evaluated (we sense what we can measure). Moreover, a focus on efficiency leads towards homogenization - indeed, variation in medical practice is used to justify EBM, which proposes ironing them out xviii_ and an adversarial relationship between doctor and patient, exacerbating our willful blindness. xi - I found (8) to be a generally excellent discussion of eugenics. I shamefully also used Wikipedia for this discussion. I owe it to Chenjie Xia (med 4) for bringing this point to my attention.

xii - Elements of these things can be found in any writing supporting EBM, (7) and (9) provide ample reference.

xiii - The evidence is usually weak. Goodman nicely backs off on this point, he really does care about evidence. On the back of his book is printed: "At its core, evidence-based practice rests on a supposition which, while probably true, itself has unclear evidentiary support". For me, what is more important is that even if EBM does provide a significant improvement to patient well-being, if that improvement is not immense, the we will always be left with the nagging question: what if we had directed all the resources currently in EBM into another endeavor - say, teaching doctors rhetoric? This sort of opportunity cost is immeasurable. Bad practice as it is to wonder about "what-if's", I just want to illustrate that this kind of decision (i.e. to go with EBM) cannot itself rest on evidence; we progress by scratching cognitive itches as they rise.

xiv - Talk and discussion with Paul Nadler, at the showing of his film Braindamadj'd, the second film of the Films that Transform series by the Whole Person Care center of McGill Medicine.

$\mathrm{XV}$ - These are directly quoted from (4), section "Limitations of EBM", p. 149. Curious to note here is that the solution to many limitations as given is "new and better EBM".

xvi - I again follow Saul here. If one reads the body of Saul's work, it's difficult not to be convinced of this point.

xvii - McGovern (4) notes this as a limitation of EBM: EBM favors interventions that attract commercial sponsorship. EBM is good for... ...those [disorders] that require a treatment or intervention that has a commercial application. Performing major RCTs properly is expensive and non-commercial research funds are scarce... ... Many potentially effective, and possibly cheaper interventions will not receive health service funding because the 'evidence is not good enough', since there was never enough money available to test the intervention properly.

xviii - Saul (3) notes that ...our economic system does try to produce the maximum quantity of goods... blunt edged products which can be aimed down the center line of established taste, flood the marketplace with... identical goods... battle of the market place cannot turn, then, on the public's comparison of products. Instead, it revolves around invisible organization strategies and visible packaging and publicity. Although medical practice is very different from a regular commercial good, the above somehow alarmed me in relation to modern pharmaceutical companies. How much a drug succeeds depends at least as much upon the maneuvering by its producing company as by its own merit. However, this is the logical conclusion of a rational 
Of course, the above does not have to happen, one can, in principle, have both rationality coupled with humanity. On the other hand, rationality, especially in our society, certainly predisposes us to such impoverishment. Some of this trade-off is simple: as molecular receptors, RCT's and genomes float to the collective medical consciousness, other things sink to the bottom. We medical students no longer read Osler as our peers did decades ago ${ }^{\mathrm{xix}}$, we can no longer quote the classics as Osler did with such ease, and he did so with every expectation that his listeners - often students like us - will be familiar with them. Other parts of trade-off are more subtle: the increase in certainty, the illusion that EBM is medicine or is what medicine strove to be across all time, means that the physician is less likely to struggle with the cosmic questions. Without this struggle, this is no motive to look to history, philosophy, and thereby mark one's own place in time. This loss of literature and historical perspective, primary vehicles of humanism, means that we are even less likely to be introspective, to assess and reflect upon the world, and yet these traits are vital to humanistic medicine.

The controversy of EBM is thus a cultural tension being felt on medical turf. EBM itself is a culturalspecific product, a child of rationalism, its goals are determined by rationalism and its methodology reflect both rationalistic strengths and weaknesses. Doubtlessly it is EBM-like practices that gave us hygiene ${ }^{\mathrm{xx}}$ and the germ theory of disease, doubtlessly EBM is at least partially responsible for medicine's loss of humanism.

A fun test for the role of culture and history in medicine is that of the Martian anthropologist on Earth. Sadly, I cannot go so far and the furthest vantage point I can manage is that of a Chinese Taoist. Zhuangzix ${ }^{x x i}$, that dreamer of butterflies and great expositor of Taoism after Laozixxii, once said: life is finite, but knowledge is infinite. To pursue the infinite with the finite, how dangerous that is! To believe that one truly knows, how extremely more dangerous that is!xxiii Taoists downplay the importance of knowledge and would be horrified at EBM, yet they are sane and have a deep, satisfying and coherent philosophy. They dislike knowledge because it distracts from the Tao, the universal Path that we can experience if we but stopped and experienced it. Mystic, yes, but wise also, I think, because formed knowledge dulls that which we cannot include in knowledge per se but can sense - be it empathy or Tao. The opening of those senses is, I believe, the path to enlightenment, which, in my opinion, is almost culturally-neutral.

\section{REFERENCES}

1. Eddy DM. Evidence-based medicine: A unified approach. Health affairs 2005 Jan; 24(1): 9-17

2. Dennett CD. Consciousness explained. New York: Little, Brown and Company, 1992.

3. Saul JR. Voltaire's bastards, the dictatorship of reason in the west. Canada: Penguin Canada, 1993.

4. McGovern DPB. Key topics in evidence-based medicine. Oxford: BIOS Scientific Publishers Ltd., 2001.

5. Goodman KW. Ethics and evidence based medicine. Cambridge: Cambridge University Press, 2003.

6. Kuhn T. Structure of scientific revolutions. Chicago: University of Chicago Press, 1996.

7. Timmermans S, Mauck A. The promises and pitfalls of evidence based medicine. Health Affairs 2005 Jan; 24(1): 18-38

8. Cullen DD. Nature vs. nurture: eugenics. Choice 2005 Nov; 43(3): 405-413.

9. Sacket DL. Evidence based medicine: what it is and what it isn’t. BMJ 1996 Jan 13; 312: 71-72.

10. Kristiansen IS, Gavin M. Evidence based medicine in its place. UK: Routledge, 2004. society with rational production. Homogeneity ensures efficiency. In fact, that our medical care is often variable is often used as a justification that we need $\operatorname{EBM}(1,5,9)$. This taken to extreme is again dangerous; it is a fallacy that reason and logic can necessarily only lead to a single decision. Such uniformity is a part of the rationalist's dream, but unlikely to be a part of the world proper - even with perfect knowledge.

xix - In fact, the Osler lecture was embarrassing in exposing how little we knew about this great man and his works, despite being at the touted home of Osler. I read the Aequinimitas soon after, and I was deeply moved by many of Osler's passages - particularly how we are "simply stage accessories in the drama [of our patients' lives]... picking up, here and there, a strutter, who may have tripped upon the stage." It is a humbling thought. I know McGill students, at least of the Osler club, read and thought Osler long ago. No parallel exist today.

xx - Goodman (5), p. 79: “...it began, of course... with Florence Nightingale and her systematic data collection ... improved sanitation would save the lives of hospitalized soldiers during the Crimean War. Her reforms ... met opposition - can you imagine it? - and it took epistemological cudgel on the order of "Those who fell before Sebastopol by disease were above seven times the number who fell by the enemy..."

xxi - I read the Chinese version, but a fair English translation can be found in http://www.religiousworlds.com/taoism/cz-text1.html, based on a translation by Herbert A. Giles. Zhuangzi is commonly thought to be the second great father of Taoism, and one of the greatest story tellers of ancient China, being extremely pithy and witty, while profound at the same time.

xxii - Zhuangzi's most famous story is one where he dreams he became a butterfly, and when he woke he is unsure whether he was dreaming the butterfly, or now the butterfly is dreaming of being Zhuangzi. Laozi is the founder of Taoism, and wrote the Dao De Jin, the primary text of Taoism.

xxiii - This is my own translation. The online translation is: Human life is limited, but knowledge is limitless. To drive the limited in pursuit of the limitless is fatal; and to presume that one really knows is fatal indeed! My translation differs primarily on the character殆, which online was translated as fatal. But death holds no fear for the Taoist, it is merely a part of the Tao. I translated the word as danger, which holds true to the etymology of the word, which derives from总, or carelessness.

xxiv - Tao literally means "path" in Chinese 